\title{
INCIDÊNCIAS ÉTICAS E EPISTEMOLÓGICAS DE FRANCIS BACON NA CONCEPÇÃO DA NATUREZA: CONTRIBUIÇÕES À EDUCAÇÃO AMBIENTAL
}

\author{
Filipi Vieira Amorim ${ }^{1}$ \\ Humberto Calloni ${ }^{2}$
}

\section{Resumo}

Trata-se da problemática ética e epistemológica estabelecida historicamente, no Ocidente, acerca da concepção de Natureza. Busca-se compreender a incidência das proposições de Francis Bacon (1561-1625) com as dimensões éticas e epistêmicas que predominam nos dias atuais. A reflexão justifica-se na medida em que se presume que a discussão problematize a perenidade de uma ética que já não se coaduna com as demandas da crise ambiental instalada.

Palavras-chave: Francis Bacon. Natureza. Ética. Epistemologia. Educação Ambiental.

\section{Resumen}

Se trata de los problemas éticos y epistemológicos que históricamente han existido en el Occidente acerca de la concepción de la Naturaleza. Intentamos comprender los efectos de las proposiciones de Francis Bacon (1561-1625) con las dimensiones éticas y epistemológicas que prevalecen hoy en día. La reflexión se justifica porque se presume que la discusión problematiza la continuidad de una ética que ya no se ajusta a las exigencias de la crisis ambiental instalada.

Palabra clave: Francis Bacon. Naturaleza. Ética. Epistemología. Educación Ambiental.

\section{Introdução}

Francis Bacon (1561-1626) é um clássico do pensamento moderno e um dos precursores do conhecido empirismo britânico, tradição seguida $e$

\footnotetext{
${ }^{1}$ Licenciado em Ciências Biológicas; Mestre em Educação; Doutorando em Educação Ambiental pelo Programa de Pós-Graduação em Educação Ambiental da Universidade Federal do Rio Grande; Bolsista da CAPES; filipi_amorim@yahoo.com.br

${ }^{2}$ Licenciado em Pedagogia e Filosofia; Mestre e Doutor em Educação pela Universidade Federal do Rio Grande do Sul; Professor e pesquisador no Programa de Pós-Graduação em Educação Ambiental da Universidade Federal do Rio Grande; hcalloni@mikrus.com.br
}

AMORIM, Filipi Vieira; CALLONI, Humberto. Incidências éticas e epistemológicas de Francis Bacon na concepção da natureza: contribuições à educação ambiental. Revista Sul-Americana de Filosofia e Educação. Número 24: maio-out/2015, p. 85-101. 
desenvolvida posteriormente por outros pensadores, como John Locke (16321704), George Berkeley (1685-1753) e David Hume (1711-1776), por exemplo.

Sabemos que as colaborações de Bacon nos campos filosófico, político, epistemológico, ético e científico, marcaram a história do pensamento ocidental; por isto, com vistas às ideias deste pensador, em suas dimensões éticas e epistemológicas, (re)visitaremos uma de suas principais obras, o Novum Organum: ou verdadeiras indicaçóes acerca da interpretação da natureza, publicado originalmente no ano de 1620 .

Nosso objetivo é compreender as influências e os vestígios, éticos e epistemológicos, desta obra nesta contemporaneidade e sua possível interlocução com a Educação Ambiental. Para tanto, defenderemos a tese de que Francis Bacon proclama a interoperabilidade mecânica da Natureza, isto é, a Natureza como sistema capaz de estabelecer relações e interações com outros sistemas, mas, num horizonte mecânico, sem vida. Porém, essa hipótese pressupõe que antes das formulações filosóficas baconianas já havia uma segmentação na totalidade das relações entre sociedade e Natureza. Sabemos que essa dissociação ocorre no caminho percorrido até o paradigma mecanicista de uma ética antropocêntrica a partir da ruptura do pensamento ocidental com a visão aristotélica de Natureza (GRÜN, 2009). Nesse viés, no Ocidente, humanidade e Natureza são sistemas separados que estabelecem relações díspares num caminho para a dominação, ou seja, nessas condições, seres humanos e Natureza não somam parte de um mesmo sistema, são partes distintas em que a Natureza é objeto de dominação e exploração.

Esse, portanto, é o exemplo de ruptura e fragmentação do que não deveria, segundo acreditamos, representar o sentido ético da relação entre seres humanos e Natureza. O Novum Organum, já num contexto de distanciamento do sentido de ligação, fortalece a dissociabilidade entre seres humanos e Natureza ela, como algo que não faz parte de nós; e nós, que não somos parte dela. Deste modo, defenderemos a ideia de que, se nossa compreensão e relação ética trilhassem o avesso do que vimos afirmando, sobre nossa leitura do que há no enfoque epistêmico baconiano, seríamos como um grande e único sistema, o que 
inviabilizaria (como veremos adiante) a visão mecanicista de Natureza da qual Bacon nos fala.

Com estes argumentos, partimos da ideia de que a relação entre humanos e Natureza não foi historicamente mantida sobre o princípio da unidade sistemática, mas num horizonte dualista, como já mencionamos: i) os seres humanos, representados pela sociedade e seus modos de vida (políticos, econômicos e culturais), não somam parte da Natureza; ii) a Natureza mecânica é recurso à disposição do ser humano, por isso, sistema a parte, passível de interoperabilidades variadas.

Após estas hipóteses (pré)estabelecidas, mostraremos que as formulações do pensador britânico alcançaram um nível ético e epistemológico que ecoa imperativamente em nossos dias, fortalecendo cada vez mais a já estabelecida dualidade Homem ${ }^{3}$-Natureza. Por este motivo, evidenciaremos a emergência de novas formulações no campo dos fundamentos da Educação Ambiental que ampliem as discussões que abrangem ética e epistemologia.

O artigo está estruturado, incluindo esta introdução, em 4 tópicos: i) Introdução; ii) Quem foi e o que propôs, Francis Bacon? - apresentaremos, aqui, uma visão geral sobre o ambiente intelectual do pensador britânico, baseados no argumento de que nenhuma produção (seja científica, acadêmica, política, intelectual, etc.) é neutra ou livre de intencionalidades; iii) Ética e epistemologia no Novum Organum - este é o momento em que discutiremos algumas ideias e princípios baconianos, evidenciando, obviamente, questões éticas $e$ epistemológicas; iv) Novum Organum e seus alcances, hoje: algumas considerações finais - neste último item finalizaremos a discussão e, sem encerrá-la totalmente, entrelaçaremos os imperativos éticos e epistemológicos da teoria baconiana em suas possíveis interlocuções com a Educação Ambiental e a relação HomemNatureza.

Vejamos, então, de onde vem e para onde nos leva Francis Bacon com seu Novum Organum.

\footnotetext{
${ }^{3}$ Quando do aparecimento de palavras como "Homem" e "Homens", referimo-nos à espécie humana, Homo sapiens, em geral, sem distinção de gênero, portanto, sinônimo de ser humano, seres humanos, humanidade.
} 


\title{
Quem foi $e$ o que propôs Francis Bacon?
}

\begin{abstract}
Os descobrimentos até agora feitos de tal modo são que, quase só se apoiam em noções vulgares. Para que se penetre nos estratos mais profundos e distantes da natureza, é necessário que tanto as noções quanto os axiomas sejam abstraídos das coisas por um método mais adequado e seguro, e que o trabalho do intelecto se torne melhor e mais correto (Bacon, 1973, p. 22, Aforismo XVIII).
\end{abstract}

Francis Bacon foi "o profeta da revolução tecnológica moderna", "o filósofo da época industrial" (ANTISERI e REALE, 1990, pp. 322, 323). Tais atribuições deram-se graças ao cenário social (econômico, político e cultural) onde Bacon viveu: uma Inglaterra pioneira na área da mineração e da indústria, vanguarda nesses setores na Europa dos séculos XVI e XVII.

De família ligada à monarquia inglesa, seu pai, Sir Nicolau Bacon, era lorde Guarda-Selos da rainha Isabel, o que garantiu a permanência e o acesso de Francis à corte, bem como seu ingresso na Universidade de Cambridge aos 12 anos. Isso, somado à convivência com a realeza e seus agregados assegurou-lhe, além de uma boa formação, um futuro político promissor, ocupando funções como membro da Câmara dos Comuns, advogado e procurador-geral da Coroa, Lorde Guarda-Selos e Lorde Chanceler, além de ter recebido títulos de nobreza como Barão de Verolme e Visconde de Santo Albano.

Mas, por trás dessa ideia de homem público que se apresenta em Bacon, um célebre membro da Sociedade Real Inglesa, há acusações de ser um representante legítimo da classe hegemônica, "do homem branco, europeu, empresário de classe média" (GRÜN, 2007a, p. 27). Já estaria inscrito, por assim dizer, o real objetivo do Francis intelectual: favorecer a classe hegemônica por meio de suas ideias. Ademais, Bacon fora acusado, em 1620 (mesmo ano de publicação do Novum Organum), por receber propina em alguns processos da chancelaria, e essa condenação lhe custou a perda do cargo político e da cadeira do Parlamento (RUSSEL, 2001). 
Os alcances da ciência e da filosofia de Bacon sempre estiveram claros, e o Novum Organum lobrigava sua verdadeira intenção: superar o silogismo aristotélico, o Organom de Aristóteles. Mesmo reconhecendo que a ciência, que até então fora responsável pelo que era conhecido, descendia de todo saber que o precedia, Bacon desqualifica o conhecimento antigo, comparando-o às opiniões de uma criança. Segundo ele, entre outras acusações, a sabedoria grega é apenas farta em palavras, mas sem resultados práticos. Bacon diz não esperar nada, nenhuma certeza, quando nos utilizamos do conhecimento antigo para obtenção da "verdade" e do saber que julgava "verdadeiro" sobre os fenômenos. E reduz com demérito a postura investigativa dos gregos, dizendo que eles "estão sempre prontos para tagarelar" (BACON, 1973, p. 46, Aforismo LXXI).

Nos escritos de Bacon há uma proposta de cultivo e de descoberta da ciência, apresentada pelo viés de dois métodos: o primeiro, "antecipação da mente"; e o segundo, "interpretação da natureza". Tais caminhos seriam fonte de geração e propagação de doutrinas e essas doutrinas levariam a sociedade - os homens ${ }^{4}$, nas palavras de Bacon - a dividir-se em dois grupos. Essa divisão, sugere o autor, apresenta-se num sentido complementar, e não num sentido de separação e inimizade entre grupos. O primeiro grupo seria formado por aqueles responsáveis pelo cultivo da ciência, e Bacon (1973, p. 14) esclarece aos que optarem por esse caminho: "seja por impaciência, por injunções da vida civil, seja pela insegurança de suas mentes em compreender e abarcar a outra via [...], a eles auguramos sejam bem sucedidos". Em seguida, Bacon deixa explícito que alguns não teriam "capacidade" para seguir o segundo caminho, e esses seriam a maioria. O segundo grupo, então, constituído por uma minoria, estaria ligado ao domínio da Natureza, seriam os mais interessados e mais animados, os que estariam em busca da vitória sobre a Natureza e de novas descobertas pelo caminho de uma nova ciência: "esses, como verdadeiros filhos da ciência, que se juntem a nós, para, deixando para trás os vestíbulos das ciências, por tantos palmilhados sem resultado, penetrarmos em seus recônditos domínios" (BACON, 1973, p. 14).

\footnotetext{
${ }^{4}$ Aqui, a palavra "homens" é utilizada para referir apenas ao homem, e não à mulher, diferente do que propomos quando utilizamos as palavras "Homem" e "Homens".
} 
A partir dessas considerações, ainda que não estivessem dispostos às investigações, seriam os membros do primeiro grupo que, a partir das atividades realizadas pelo segundo grupo, atuariam como vetores de tais resultados alcançados no que condiz ao domínio da Natureza. E, neste sentido, paradoxalmente, Bacon afirma que o "saber verdadeiro" e a "capacidade" de alcançá-lo não está disponível a todos, cindindo a potência intelectual do saber humano pelo exercício investigativo, ou seja, por mais que todos os homens estejam empenhados em alcançar o conhecimento e a "verdade" contida nos fenômenos, apenas uma minoria é capaz de tal atividade.

O paradoxo está nitidamente exposto quando Bacon anunciou, como mencionamos, que a separação da sociedade em dois grupos seria complementar, mas o que vimos é a negação do conhecimento a determinada parcela da sociedade, representada pelos "homens da ciência". Os membros do primeiro grupo não são os guardiões do "saber verdadeiro", não são os privilegiados, não são os que "nasceram para saber": o primeiro grupo, "antecipação da mente", é formado pelos propagadores das doutrinas e das descobertas feitas pelo segundo grupo, "interpretação da natureza". Queremos, com isto, enfatizar a dimensão "classista" das proposições baconianas, os ideais de poder e dominação de uma classe sobre outra que, em si, apontam os interesses primários primados na dominação da Natureza: o favorecimento de uns em detrimento de outros.

No Aforismo XXX, Bacon (1973, p. 25) afirma que "não se lograria grande progresso nas ciências" através das "antecipaçôes da mente", "porque os erros radicais perpetrados na mente [...] não se curariam nem pela excelência das operações nem pelos remédios subsequentes", ou seja, se o grupo da “interpretação da natureza", que detém o método de alcance à "verdade", não trabalha e depois transfere o conhecimento "verdadeiro" ao outro grupo, não há o avanço da ciência e da dominação da Natureza. As antecipações são o método corrente, diz Bacon. Por isto, afirmamos que nesse ideal da ciência baconiana há necessidade de distinção grupal, para que um grupo imponha a "verdade" ao outro grupo e o senso comum seja transformado pelos saberes manipulados da 
ciência. Eis que cai por terra qualquer falsa ideia de neutralidade do cientista, pesquisador, etc., pois vimos, aqui, as intencionalidades das proposições de Bacon.

Ademais, essa ruptura da sociedade em dois grupos é a veleta que indica o rumo para o desenvolvimento da ciência baconiana. De modo que outras aplicações filosóficas eram inúteis e estariam facilmente ao alcance dos homens, sua filosofia de aplicação científica buscava a vitória sobre a Natureza; da ideia paradoxal de união dos homens à dominação da Natureza; da maioria envolvida com o cultivo da ciência à minoria na investigação, descobrimento e domínio desta; de um lado, homens detentores do saber, socialmente privilegiados, do outro, homens de mentes inseguras, cuidadores e vetores dos novos e manipulados saberes científicos.

A preocupação de Bacon com a busca pelos novos modos de investigar para conhecer o fizeram, (re)correntemente, desconsiderar o saber que o precede. $\mathrm{E}$ assim, além de negligente quanto à importância do caminho investigativo percorrido pelos gregos e sua relevância para o pensamento ocidental, passa a criticar o silogismo aristotélico e prescreve a rejeição aos conhecimentos humanos prévios, os pré-conceitos, prejulgamentos acerca do que se quer compreender dimensões dos saberes que julgou unicamente como "hábitos pervertidos, já profundamente arraigados na mente" (BACON, 1972, p. 15).

O argumento do filósofo é que no ato da descrição da verdade, da realidade, da investigação, as pré-concepções que o sujeito carrega são confusas, $e$ isso não pode garantir a exatidão dos fatos concretos. "Ademais, o fim e a meta da ciência foram mal postos pelos homens" (BACON, 1972, p. 55, Aforismo LXXXII). Um fenômeno real e verdadeiro, segundo sugeriu Bacon, deve ser alcançado por um método mais seguro: somente assim seria factível a possessão da Natureza. Por isso, o caminho sugerido no Novum Organum é tecido por vários Aforismos, que se resumem em breves sentenças, apotegmas, formadas por poucas palavras que concluem pensamentos contínuos e fragmentados.

Entre seus posicionamentos teóricos, científicos e filosóficos, além da presença constante da crítica aos gregos e ao saber que o antecede, Bacon descreveu com tenacidade sua Teoria dos Ídolos. Segundo suas descrições, existem 
quatro grupos de ídolos: i) os ídolos da tribo; ii) os ídolos da caverna; iii) os ídolos do foro, ou dos foros públicos, ou da praça pública, ou do mercado; iv) os ídolos do teatro. Cada grupo de ídolos tem uma característica principal, mas, de forma resumida, os ídolos representam as falsas opiniões inculcadas no ser humano. Seriam os responsáveis por desencadear crenças místicas, astrológicas, alquímicas; estariam ligados à influência que sofremos pelos costumes, pela educação e pelo uso da linguagem pública e comum.

Bacon quer uma reforma no intelecto humano, seres capazes de juízo próprio, desligados dos pré-conceitos imersos na atribuição dos ídolos. A proposta fundamental é a limpeza e a superação das noções geradas pela ascendência dos ídolos, pois só assim seria possível imperar o conhecimento verdadeiramente científico do mundo. Destarte, eis o caminho oferecido por Francis Bacon, no Novum Organum, que nos deixa a ideia de repulsa aos pré-conceitos como conhecimento histórico e estabelecido naturalmente na tradição, nas variadas relações humanas com o que chamou ídolos, pressupondo que esse é o único caminho para conduzir o homem ${ }^{5}$ à "verdade".

Até agora, vimos o projeto ético e epistêmico pensado por Bacon para a sociedade composta por homens dominadores do saber e homens doutrinados, vetores do conhecimento que estaria sempre acabado, fechado nas proposições de determinado grupo. Igualmente, vimos seu ideal ao que comporta a relação do Homem com a Natureza. É a partir dessas análises que percorremos o próximo item de discussão, entrelaçando conceitos éticos e epistemológicos.

\section{Ética e epistemologia no Novum Organum}

Todo estudioso da natureza deve ter por suspeito o que o intelecto capta e retém com predileção. Em vista disso, muito grande deve ser a precaução para que o intelecto se mantenha íntegro e puro (BACON, 1973, p. 34, Aforismo LVIII).

\footnotetext{
${ }^{5}$ Quando utilizamos a palavra "homem" e "homens" evidenciamos o caráter machista representado pelo cientificismo da Idade Moderna, tal como explicou Grün (2009, p. 23).
} 
A verdadeira e legítima meta das ciências é a de dotar a vida humana de novos inventos e recursos (BACON, 1973, p. 55, Aforismo LXXXI).

Para expormos nossa leitura quanto à presença de uma Natureza mecânica e interoperável no Novum Organum, salientaremos duas ideias principais correspondentes a esse subtítulo, a saber: i) a negação da tradição; ii) o domínio da Natureza.

Essa escolha se fez pelo fato de que tanto a ideia de domínio da Natureza quanto a negação da tradição filosófica e científica são os fluxos correntes nos escritos de Francis Bacon (GRÜN, 2007a; 2009). Isso denota, ao mesmo tempo, um pressuposto epistemológico e uma dimensão ética para pensarmos a Educação Ambiental. Acontece que, "na verdade, ética e epistemologia são indissociáveis, pois não se pode separar o saber dos valores (GRÜN, 2007b, p. 187). Assim, trilhamos contra a corrente da teoria baconiana de duplo alcance, ético $e$ epistemológico, para sustentarmos o argumento de que suas proposições são influentes ainda hoje, tanto na produção do conhecimento científico como na dimensão ética das relações entre seres humanos e Natureza.

Além do que expomos no subtítulo anterior - Quem foi e o que propôs, Francis Bacon? - cabe salientarmos outras características históricas que marcaram o pensamento baconiano. Essa necessidade se dá a fim de encontrarmos, neste recorte necessário, a chave para a compreensão do significado ético e epistêmico do Novum Organum.

O primado da teoria baconiana deu-se num ambiente onde os princípios da teonomia medieval do Ocidente flutuavam com dificuldade e sob o risco certeiro do naufrágio. Destarte, o ponto inaugural no Novum Organum fora a crença no desenvolvimento e no progresso da sociedade pelos ditames empíricos e analíticos de uma nova ciência. "Em suma", disse Bacon (1972, p. 55, Aforismo LXXXI), "se ninguém até agora fixou de forma justa o fim da ciência, não é para causar espanto que tudo que se subordine a esse fim desemboque em uma aberração".

Essa atmosfera epistêmica foi fruto do processo de esvaziamento da racionalidade teocêntrica que, dando lugar ao vigor $e$ às promessas do 
antropocentrismo, punha os seres humanos a pensarem sobre si e a elaborarem respostas aos fenômenos até então misticamente explicados pela fé. Isso ocorreu porque a ideia de um Deus, que antes tudo explicava, conhecia e regulava, por Sua natureza e totalidade Onipresente, Onipotente e Onisciente, foi fragilizada. Assim, na época de Francis Bacon e dos primórdios da ainda tímida modernidade cientificista, os homens precisavam de técnicas e métodos que fossem capazes de provar, racionalmente, com explicações sobre causas e efeitos, os fenômenos da Natureza e da própria vida social.

Daqui partimos com a dupla mudança: ética e epistemológica. A ruptura com o saber que precede a ciência moderna ofereceu novos rumos para o conhecimento, bem como foram precursores de uma nova postura ética na convivência entre humanos e em suas relações com a Natureza. Assim, se o saber filosófico dos gregos na antiguidade clássica sobreviveu, de certa forma, aliado aos saberes teocêntricos da Idade Média, essa aliança perde espaço quando da revolução científica operada pela ciência emergente na modernidade. Nisso não atribuímos responsabilidade única ao Novum Organum, visto que a mudança paradigmática entre medievo e modernidade foi resultado de um amplo movimento da comunidade científica e filosófica da época, num desenvolvimento que atravessou, seguiu e segue, séculos. Entre os pensadores que colaboraram nesse processo, destacamos: Nicolau Copérnico (1473-1543); Agripa de Nettesheim (1487-1535); Michel de Montaigne (1533-1592); Pierre Charron; (1541-1603), Francisco Sanchez (1552-1632); Galileu Galilei (1564-1642); Jean Kepler (1571-1630); René Descartes (1596-1650); e Isaac Newton (1642-1727).

Embora com fragilidades já apontadas por teóricos contemporâneos, esse movimento da ciência e filosofia modernas segue em desenvolvimento. Mas, em resumo, afirmamos que o movimento ético e epistemológico que surge com a Idade Moderna e seus modos de ver, pensar, e estar no mundo, são resultados de uma ampla gama de interpretações cientificas e filosóficas de horizonte comum: o ser humano como centro do mundo, responsável pelo saber de si e do universo que o cerca. 
Portanto, do mesmo modo como fizeram outros pensadores, precursores da modernidade científica, Bacon deu ênfase a um método que mediaria os homens em seus processos de alcance das verdades. Seu caminho intenta percorrer, com distanciamento dos ídolos, a trilha correta para que seja mantida a pureza do intelecto e não ocorra o infortúnio do erro.

Sobre a filosofia que o precede, Bacon enfatizou três modelos: i) sofística; ii) empírica; iii) supersticiosa. Para tais buscou uma superação, característica que acentua a negação e a desvalorização para com as tradições filosóficas advindas da Idade Antiga e da Idade Média.

É importante, aqui, resgatarmos o sentido daquilo que vimos chamando "tradição" - bem como anunciamos no início deste item "Ética e epistemologia no Novum Organum" -, pois adiante daremos maior ênfase nesta questão.

Se Bacon viu a tradição como herança negativa ao avanço dos saberes, o filósofo alemão Hans-Georg Gadamer (1900-2002) tem postura incongruente a tal sugestão, e é esta a ideia de tradição que defendemos. A tradição, diante do que nos sugere Gadamer (2005) está vinculada ao nosso modo de vida e estabelecida de forma natural ao nosso ser, isto é, não há como escaparmos da tradição. Para Gadamer (2005, p. 372), o ser, histórico e finito, pode estabelecer novas formas de saber e de viver, mas isso não garante total discernimento e ruptura com a tradição: "É isso, precisamente, que denominamos tradição: ter validade sem precisar de fundamentação". Ou seja, temos e queremos assegurar o impacto salutar da existência de um horizonte histórico a ser considerado, diferente do que conseguiu promover, com sua teoria, Francis Bacon. Além disto, podemos dizer que aproximar o pensamento moderno com o pensamento grego é para todos nós, para toda a cultura ocidental, uma espécie de encontro conosco mesmos (GADAMER, 2000; GADAMER, 2001).

Vejamos, agora, as críticas baconianas - segundo sua categorização - a cada modelo filosófico que o precede, os quais estão enquadrados entre os ídolos do teatro - aqueles que foram, no intelecto, "abertamente incutidos e recebidos por meio de fábulas" (BACON, 1973, p. 36, Aforismo LXI). 
Ao primeiro modelo, da sofística, Bacon atrelou o nome de Aristóteles, entre outros, e chamou, igualmente, esse sistema filosófico de escola racional. Sua crítica remete ao argumento de que os filósofos (que chamou sofistas) ou se propunham "muito a partir de pouco ou pouco a partir de muito" (BACON, 1973, p. 37, Aforismo LXII). Salientou que a estrutura para as afirmações filosóficas no modelo sofístico estiveram assentadas numa base estreita, com insuficientes $e$ indesejáveis números de dados, e com experimentos que não ultrapassaram a vulgaridade. Sobre Aristóteles, na concepção baconiana, repousa a dúvida exposta em palavras, nada além de respostas elaboradas que são negligentes com o mais íntimo daquilo presente na verdade das coisas.

Sabemos que os chamados sofistas eram pensadores contemporâneos de Sócrates (469 a.C. ou 470 a.C. - 399 a.C.), mestres da retórica, os quais eram criticados pelo próprio Sócrates e outros filósofos, seus discípulos, por não terem uma conduta ética, visto que ensinavam, com custos ao aprendiz, a vencer disputas conceituais e argumentativas sem um horizonte ético presente, mas de acordo com interesses individuais. Bacon nomeia Aristóteles (384 a.C. - 322 a.C.) como um dos sofistas, mas trata de uma delimitação que engloba, em partes, a filosofia e os filósofos da Grécia Antiga, sem que faça a devida distinção histórica entre os sofistas e os filósofos. Defendemos isto com base nas distinções feitas por Platão (428 a.C. - 348 a.C.), que não atribuía aos sofistas o epíteto de filósofos (PLATON, 1966).

Para Bacon (1973, p. 46, Aforismo LXXI), todos os filósofos antigos são vistos como sofistas, diferente da distinção de Platão; em suas palavras:

[...] o nome de sofistas, que foi depreciativamente aos que se pretendiam filósofos e que acabou por designar os antigos retores, Górgias, Protágoras, Hípias e Polo, compete igualmente a Platão, Aristóteles, Zenão, Epicuro, Teofrasto [...]. Entre eles havia apenas esta diferença: os primeiros eram do tipo errante e mercenário, percorriam a cidade ostentando a sua sabedoria e exigindo estipêndio; os outros, do tipo mais solene e comedido, tinham moradas fixas, abriram escolas e ensinaram filosofia gratuitamente. 
Embora tenhamos esses dois pontos de vista, nos opomos à classificação baconiana. Defendemos, como Platão, a diferença entre os sofistas e os filósofos, sobretudo pela dimensão ética das abordagens entre esses dois grupos de pensadores.

Na sequência da exposição sobre o repúdio à tradição, Bacon caracterizou a escola empírica. Nesse segundo caso, utilizou adjetivos como "monstruoso", "obscuro" e "disforme", sobre as teorias elaboradas nessa filosofia empírica e, igualmente, sobre seu campo de investigação e conhecimento produzido. Para Bacon (1973, p. 39, Aforismo LXIV), os que praticam esse modelo epistêmico contaminam sua imaginação e, por isso, têm por certo (embora "errados") os saberes construídos nesse coletivo: "mas aos demais [a escola empírica] apresentase como indigna de crédito e vazia".

Mais adiante, Bacon proclama, quanto à união entre as escolas sofística $e$ empírica, que isso seria um "grande perigo [...], e contra ele nos devemos acautelar desde já". Com isso, o pensador britânico refere-se ao terceiro modelo, o supersticioso, visto a apropriação que fez o pensamento medieval sobre alguns dos saberes da Idade Antiga. Sua crítica permanece com foco no fato dessa última, filosofia antiga, a sofística ou racional, ter sido abarcada pelo que chamou filosofia empírica, dando origem à escolástica, representada, entre outros, por Santo Agostinho (354-430) e São Tomás de Aquino (1225-1274). Essa união teria causado a "corrupção da filosofia, advinda da superstição e da mescla com a teologia" (BACON, 1973, p. 39, Aforismo LXV).

O posicionamento baconiano para com a tradição filosófica é claro, e daí seu posicionamento epistemológico contra os mitos, as superstições $e$ as explicações dadas pela fé e o saber teológico. As filosofias e escolas filosóficas, de que discorremos anteriormente, são, no Novum Organum, ausência de sobriedade e impedimento ao avanço da ciência para o bem-estar do homem.

$\mathrm{Na}$ continuidade do ensaio, veremos que essa dimensão que busca apagar e esquecer as tradições científica e filosófica são, ainda hoje, dignas de investigações, sobretudo por seu caráter, infelizmente, atual. 


\section{Novum organum e seus alcances, hoje: algumas considerações finais}

[...] Francis Bacon inaugura, no século XVII, aquela que seria uma das características presentes em todo o projeto moderno: a ausência de historicidade e a atividade humana colocada na perspectiva de um presente puro, liberto da tradição, considerada nefasta pela ciência (GRÜN, 2007a, p. 29).

Bacon promoveu uma concepção utilitária de ciência na qual a natureza é considerada apenas quanto ao seu valor de uso (GRÜN, 2009 p. 71).

Nestas considerações finais, não temos a pretensão de encerrar esta discussão; pelo contrário, queremos afirmar a importância das discussões epistemológicas que tratem direta ou indiretamente da Educação Ambiental. Do mesmo modo, a tratativa filosófica, ética e epistêmica, acerca da relação HomemNatureza, vai ao encontro da discussão que permeia o campo da Educação Ambiental.

No caso específico do Novum Organum, como tratamos neste ensaio, temos a impressão de que o legado ético e epistemológico da obra é a noção única de que o ser humano é dono do mundo, ou seja, a partir da concepção baconiana, a sociedade moderna faria com que a ciência se aplicasse à indústria e que o saber se aplicasse à prática, em benefício do Homem. E esse é o modo pelo qual ainda se dão as relações entre Homem e Natureza. O ser humano, nesse cenário, ocupa posições de dominador e explorador, onde é impossível a manutenção do respeito e do sentimento de dependência como relação ética.

Do mesmo modo, no que se refere ao esquecimento da tradição e dos pressupostos epistemológicos - da crença de que os caminhos trilhados pelos filósofos e pela ciência antiga não ofereceram aos Homens um domínio sobre a Natureza - Bacon acredita que só a partir do momento em que nos libertássemos do passado teríamos poder sobre a Natureza. Grün (2007a, p. 38) afirma que isso anula a possibilidade de colocarmos a questão ambiental em uma perspectiva histórica, o que promove uma "presentificação do pensamento". 
Tratar o presente numa perspectiva desvinculada da histórica também é uma "invenção" da modernidade e, como vimos, é presença constante nos textos de Bacon. Sendo assim, a presentificação não só nega o passado como coloca em risco o futuro, pois o presente, o hoje, está acima de tudo, e o passado já não serve para nada. A partir da negação de dependência que há entre Homem e Natureza, o ser humano só se sente incluído na Natureza quando em posição de dominador. Seria, então, a presentificação uma das causas da crise ambiental contemporânea?

Afirmamos que sim. Vivemos, na sociedade contemporânea, a ideia do presenteísmo, do hoje, do imediatismo, e nesse ponto a dimensão ética da Educação Ambiental fica comprometida. Quando não há historicização, as esferas que condicionam o social, como a economia, a política e a cultura, por exemplo, são esquecidas. E é esse esquecimento que estimula a interoperabilidade mecânica da Natureza. Aqui, determinamos essa interoperabilidade como mecânica, dadas as condições com que o pensamento baconiano se desenvolveu, dentro de uma ética antropocêntrica que limita e nega o caráter vivo e orgânico da Natureza. As acusações de Bacon ao pensamento aristotélico, como vimos anteriormente, suplantam a lógica da interdependência que um dia houve na relação HomemNatureza.

Se a Natureza é interoperável, é porque a ética antropocêntrica é capaz de torná-la interoperável. Daí os laços que nos certificam esta afirmação. A interoperabilidade é fruto do esquecimento da dimensão ética, por sua vez resultado do apagamento da tradição e do fortalecimento do presenteísmo. Toda a discussão proposta por Bacon dá-se em nome do fortalecimento de uma ciência para o hoje e para o futuro, para o avanço da dominação da Natureza num horizonte que é ecologicamente insustentável.

E esta interoperabilidade pode ser positiva se aliada a ética? Cremos que dificilmente é possível um total resgate da historicidade perdida. Defendemos que a Educação Ambiental seja problematizadora desta questão, colocando, sobretudo, em evidência o caráter histórico do conhecimento e da produção deste, seja atual ou antigo. Se hoje temos uma interoperabilidade mecânica, consequentemente negativa ao convívio e à relação Homem-Natureza, é graças à negação da tradição 
que esquece, por si mesma, a dimensão ética dos processos que ligam humanidade e Natureza. "A educação ambiental deveria então promover uma reintegração dos humanos ao seio dessa natureza" (GRÜN, 2009, p. 71).

Aqui surge a possibilidade de estabelecermos uma discussão que busque um retorno ao orgânico em contraposição ao mecânico, pois Bacon estabeleceu uma espécie de fisiatria com a Natureza, ou seja, só com a instauração de novos saberes e de um outro modo de relação com a Natureza a ciência seria capaz de avançar e beneficiar sem limites a vida humana. Isso significava, como vimos, para o pensador britânico, uma restauração nos domínios dos saberes para o fim do conhecimento vultoso. E essa aliança ética e epistemológica ratificou o domínio da nova ciência sobre a Natureza.

Não basta, para o avanço da ciência e da filosofia modernas, que os homens investiguem o si mesmo da Natureza; há que se (re)buscar o oculto, operar o inalcançado, e tudo isso pelo método que mantém o intelecto intacto, puro, livre da influência dos ídolos.

Como palavras finais, não atribuímos o problema emergente da crise ambiental contemporânea, unicamente, a Francis Bacon, como já mencionado. Esta afirmação descaracterizaria toda a complexidade de tal problemática, dandolhe ares reducionistas. Mas, o conteúdo apresentado pela proposta de domínio da Natureza, tendo por método o empirismo, agrupado às severas negações quanto à validade da tradição, permite-nos ver no pensamento baconiano o impulso para o rudimento dos alcances sobre a dominação da Natureza.

O mundo e a Natureza, segundo o projeto baconiano, não passam de estruturas mecânicas que devem impulsionar o avanço da ciência, enquanto aplicação prática, sempre em benefício do Homem e do progresso tecnológico a qualquer custo. Alcançar o conhecimento para dominar a Natureza significa saber; ser dotado de saber é garantir o poder sobre a Natureza e sobre o mundo. Daí a famosa máxima baconiana: saber é poder. 


\section{REFERÊNCIAS}

ANTISERI, Dario; REALE, Giovanni. História da filosofia: do Humanismo a Kant. São Paulo: Paulus, 1990.

BACON, Francis. Novum organum. São Paulo: Abril Cultural, 1973.

GADAMER, Hans-Georg. Verdade e método I: traços fundamentais de uma hermenêutica filosófica. Petrópolis: Editora Vozes, 2005.

GADAMER, Hans-Georg. La filosofia griega y el pensamiento moderno. In: El inicio de la sabiduría. Barcelona: Editorial Paidós, 2001.

GADAMER, Hans-Georg. A filosofia grega e o pensamento moderno. In: ALMEIDA, Custódio Luís Silva de; FLICKINGER, Hans-Georg; ROHDEN, Luiz. Hermenêutica filosófica: nas trilhas de Hans-Georg Gadamer. Porto Alegre: EDIPUCRS, 2000.

GRÜN, Mauro. Em busca da dimensão ética da educação ambiental. Campinas: Papirus, 2007a.

GRÜN, Mauro. Ética e educação ambiental: a conexão necessária. Campinas: Papirus, 2009.

GRÜN, Mauro. A pesquisa em ética na educação ambiental. Pesquisa em Educação Ambiental (UFSCar), v. 2, p. 185-205, 2007 b.

PLATON. Platon obras completas. Madrid: Aguillar, 1966.

RUSSEL, Bertrand. História do pensamento ocidental: a aventura dos présocráticos a Wittgenstein. Rio de Janeiro: Ediouro, 2001. 